\title{
Acceptability of Physician Associate Interns in Primary Care: Results from a Service Evaluation
}

Elizabeth Cottrell ( $\square$ e.cottrell@keele.ac.uk)

Keele University https://orcid.org/0000-0002-5757-1854

\section{Victoria Silverwood}

Keele University School of Medicine

\section{Alex Strivens-Joyce}

Montgomery Medical Practice

\section{Lucy Minshull}

North Staffordshire GP Federation

John J Edwards

Keele University School of Medicine

\section{Sarah Lawton}

Keele University School of Medicine

Matt Aiello

Health Education England

Sharon Turner

North Staffordshire GP Federation

\section{Research article}

Keywords: Physician associate, internship, primary care, evaluation

DOI: https://doi.org/10.21203/rs.3.rs-70741/v1

License: (c) (i) This work is licensed under a Creative Commons Attribution 4.0 International License.

Read Full License 


\section{Abstract}

Background: Physician associates (PA) form part of the policy-driven response to increased primary care demand and a general practitioner recruitment and retention crisis. However, they are novel to the primary care workforce, have limitations such as being unable to prescribe and order ionising radiation investigations, and there are very limited directly-relevant data to guide the integration of PAs into primary care. To address this, a novel internship scheme was established in Staffordshire to support PAs entering primary care. This evaluation was designed to establish the acceptability of Physician Associate (PA) Interns within primary care.

Methods: The Staffordshire PA Internship (SPAI) scheme was introduced in Staffordshire in 2017. PAs were concurrently working in primary and secondary care posts for one year, with protected weekly education sessions to equip them for work in primary care. Within the nine primary care practices hosting 10 PA interns in the first two cohorts, the PA interns, supervising GPs and practice managers, and patients who attended an appointment with a PA intern were invited to participate in the evaluation.

Results: By evaluation end, eight of the ten PAs had completed the internship. Overall PA interns were acceptable to practices and patients, however there was ambiguity about the PA role itself, and how best to communicate this, as well as how to operationalise their roles. An expectation-preparedness gap was identified for PAs working in primary care. This resulted in high levels of supervision required for PA interns early within the internship. The internship provided a platform upon which the expectationpreparedness gap could be closed and made the high supervision requirements more acceptable to practices.

Conclusions: This test-of-concept SPAl has highlighted that, to ensure successful integration of new PAs into primary care and to support them to reach their full potential, commitments to longer-term, sustainable, cohesive and appropriately funded schemes, including structured and standardised education and supervision, need to be delivered. Without such investment, there is a risk that acceptability of PAs in primary care, and PAs' views of primary care careers, will be undermined before the profession has attained its full potential.

\section{Background}

Physician Associates (PAs) are dependent healthcare professionals, who have been trained in the medical model[1]. Until 2018 there were fewer than 200 PAs working in UK primary care[2, 3]. PAs can work in primary care immediately upon graduation, although an accountable GP must be constantly available for support and prescription authorisation. There has been a dramatic policy-driven[4] increase in student PAs, from 80 students across three UK higher education institutions (HEI) in 2014 to 1800 students across 35 UK HEl in September 2019. This positioned the workforce to deliver the NHS Long Term Plan[5] through Primary Care Networks (PCNs)[6, 7]. 
Available data are predominantly based on USA-trained primary care PAs; a more established workforce able to prescribe and order radiographs[8]. Whilst PAs have been introduced as a rapid and relatively inexpensive way to grow the UK primary care workforce, little is known about their clinical effectiveness, potential for return on investment[9], the integration of newly qualified PAs ('new PAs') into the UK workforce nor their acceptability to patients and primary care healthcare professionals.

Workforce leads in Staffordshire recognised the potential for primary care PAs in 2016 to support a significant GP-workforce crisis[3]; several practices were becoming unsustainable and were facing closure. However, to promote successful, safe integration of PAs into primary care roles, it was felt necessary to provide a structured and supportive postgraduate programme; a primary care PA internship scheme for fully qualified 'new PAs'. Within an external evaluation designed to establish how an internship could support the integration of PAs within primary care teams, the results presented in this paper report the acceptability of PA interns in primary care.

\section{Methods}

\section{The Staffordshire Physician Associate Internship (SPAI)}

The innovative SPAl was created and delivered by the North Staffordshire GP Federation (NSGPF) in partnership with five NHS trusts across Staffordshire, with a single lead employer. Investment was provided jointly by Health Education England (HEE) and NHS England (NHSE) to enable PA intern (henceforth, 'intern') posts to be subsidised and to defray costs of training and malpractice insurance. The SPAI was designed as a single-year, pilot, test-of-concept, split-post scheme in which interns spent: half the week in primary care, two days in secondary care, and half a day undertaking protected learning. Interns remained in the two clinical posts, concurrently, for the whole year. Seven intern cohorts have been hosted to date.

\section{Data collection}

Evaluation participants were interns and host-practice staff and patients from the first two SPAl cohorts (commencement October 2017 and March 2018). Evaluation data were gathered according to domains within Lau et al.'s conceptual framework for implementing interventions in primary care[11]. One evaluator (EC) collected data at cohort start, mid-point and end. Intern data collection occurred through both questionnaire surveys and discussion groups. Host-practice data (practice managers and/or the lead GP for the intern), were collected through in-practice discussions. Patient acceptability data were collected by practices at one time-point (May-September 2018) using a practice-delivered patient survey, adapted, with permission, from the IPSOS Mori patient survey[12]. Anonymous patient responses were forwarded to the evaluation team.

\section{Data Analysis}

Verbal data were audio recorded and transcribed. Results from both cohorts were combined. Closed and multiple-choice survey responses were coded in IBM SPSS and descriptively analysed. Open responses 
that mapped to survey data were coded and amalgamated into quantitative evaluation data-sets. Open responses from discussions and survey data were thematically analysed within NVIVO using our evaluation framework, developed from Lau's framework[11] such that: 'external context' included local and national health economies and policy, 'organisation' included data relating to host-practices, 'professional' related to the intern and 'intervention' was the SPAI. Concepts were independently identified and coded by two evaluators (EC and VS). The evaluation framework remained fixed and sub-themes and concepts were developed iteratively, mapped together, and areas of agreement and dissonance were identified.

\section{Results}

Ten interns commenced the two cohorts. At evaluation end: eight had completed the internship, one left the SPAl early for a primary care job elsewhere and one was on maternity leave. Eight interns were new PAs. Among the other two, one had been working in primary care for a few months and another on a respiratory ward. One practice hosted an intern in both cohorts. Overall, data were collected from all interns at baseline (seven gave data at every time-point), eight practices at baseline (six gave data at every time-point), and 165 patients from five practices. Key themes relating to the acceptability of interns in primary care are described below.

\section{Conceptualisations of interns}

While individual interns integrated as well-liked team members, both interns and practices lacked clarity about what a PA is, let alone an intern, and/or how best to communicate this to patients and colleagues. Three common conceptualisations of interns were: what they were not (e.g. not a doctor or a nurse); what they were similar to (e.g. salaried or trainee GPs, medical student); or what they could not do (e.g. they cannot prescribe). Conceptualisations of what they were, and positive statements about their role, were lacking.

Receptionists' misunderstanding about interns caused inefficiencies; the 'wrong type' of patients being allocated to interns. Dissatisfaction arose if practices had greater expectations of autonomy (e.g. interns are similar to a trainee GP). Although on reflection, these expectations were recognised as being unrealistic, practices highlighted existing literature outlining potential roles of (experienced) PAs[13] as contributing to these perceptions. Patients valued consultations with interns but lacked clarity about the professional they had seen. Interns recognised this. Forty-seven (29\%) responding patients reported that they did not know they were seeing a PA.

Interns considered themselves most similar to GPs, although recognised they were not GP replacements. GPs agreed that interns adopted a similar approach to patient assessment and presentation, but thought interns had less depth of understanding and reduced ability to diagnose and consistently manage complex conditions. 
Whilst interns had some gaps in their capabilities, compared with trained GPs (the lack of prescribing capability was mentioned repeatedly), their flexibility to perform elements of different healthcare professionals' roles was valued by GPs and practice managers. Overall, interns were perceived as a hybrid of multiple primary care roles.

\section{Box 1 Quotes illustrating views regarding the conceptualisations of interns}

"No 'cause if we say... Physician's Associate. And what's one of them? [laugh]... isn't a doctor... isn't a nurse...in-between but he can do most things." (Practice Manager)

"I see [the PA]... Half-way between a nurse which is looking at pure clinical... whereas a GP...is... more holistic with a bit of social care added in there" (Practice Manager)

"... [the PA is] not working as a registrar. [the PA is] working as a medical student..." (Practice Manager)

"Like that hypothetical deductive model?...No I don't think [the PA is] there. I think [the PA is] taught a bit like a third year medical student...these are the questions you ask about chest pain. . ." (General Practitioner)

"...I really like...the flexibility of a PA. There's nothing they can't really do, obviously there's the prescribing bit, but actually can they visit? Yes...Could they see children? Well yes they can in time... There's been no resistance. [the PA has] just - well show me what to do and I'll do it." (General Practitioner)

"...it said physician associate on the door and not doctor...have you not got all your stripes yet?...they keep calling you doctor and you keep saying just stop there." (PA intern)

"The doctor was easy to listen to and explained everything well, easy to understand, very pleased with the doctor" (Patient)

\section{Perceptions of the PA role in primary care}

The lack of a clear, realistic description of the primary care roles that interns were equipped to undertake caused uncertainty and confusion amongst some practices and patients. Practices often relied on interns to outline their own professional boundaries. Confusion over PAs being independent or dependent practitioners emerged. Practices often recognised that interns were dependent on GPs for supervision, but lacked clarity about the wider implications of this (e.g. the process for administration of influenza vaccinations). Some practices described uncertainty among existing staff about the role(s) an intern would occupy. However, despite lack of role clarity, host-practices saw the subsidised internship as an opportunity to explore something 'different'. Practices adapted to supervision requirements through a dynamic approach to intern tasks, generally increasing the proportion of time interns undertook patient reviews and non-clinical activities. By internship end, practices were developing conceptualisations of future, higher-level implementation of a PA. 


\section{Box 2 Quotes illustrating perceptions of the PA role in primary care}

"Am I utilising him correctly as the Internship is expecting us to do?" (Practice Manager)

'there's sort of no singular PA job description... There's a broad range of things that they can do but it's making sure that the person...can do what you want them to do and they're happy to do it.' (Practice Manager)

"I think they bring something different... they really sit between somewhere like a nurse practitioner and a junior doctor... When you get a very experienced $P A$, then they certainly are going to be like a good junior doctor." (Practice Manager)

"...there's lots of things that they can assist us with...things like phoning patients on our behalf... rather than just seeing their own patients - helping us with our patients..." (General Practitioner)

\section{Preparedness of interns for primary care: the expectation- preparedness gap}

This evaluation uncovered a significant expectation-preparedness gap. All interns expected to undertake book-on-day (BOD) appointments in primary care, though only $44 \%$ came into the internship with this experience. Similarly, $89 \%$ of interns had expected to do long-term condition reviews but only $22 \%$ had prior experience (Table 1). Interns were under-equipped on internship commencement to manage primary care patients with undifferentiated, complex, multi-morbidity.

Table 1: Expected and actual roles compared to previous experience in primary care - the expectationpreparedness gap 


\begin{tabular}{|c|c|c|c|c|c|}
\hline Potential roles & $\begin{array}{c}\text { Experience } \\
\text { prior to } \\
\text { Internship }(n=9)\end{array}$ & $\begin{array}{c}\text { Expectation- } \\
\text { preparedness } \\
\text { gap }\end{array}$ & $\begin{array}{l}\text { Expected to do } \\
\text { at baseline } \\
(n=9)\end{array}$ & \multicolumn{2}{|c|}{$\begin{array}{l}\text { Undertaking at } \\
\text { end of the } \\
\text { Internship } \\
(n=7)\end{array}$} \\
\hline \multicolumn{6}{|c|}{ Clinical contact activities } \\
\hline $\begin{array}{l}\text { Book-on-day } \\
\text { (acute) } \\
\text { appointments }\end{array}$ & $44 \%$ & & $100 \%$ & $86 \%$ & $\downarrow$ \\
\hline $\begin{array}{l}\text { Long term } \\
\text { condition } \\
\text { reviews }\end{array}$ & $22 \%$ & & $89 \%$ & $71 \%$ & $\downarrow$ \\
\hline Home visits & $33 \%$ & & $78 \%$ & $86 \%$ & $\uparrow$ \\
\hline $\begin{array}{l}\text { Pre-booked } \\
\text { (routine) } \\
\text { appointments }\end{array}$ & $56 \%$ & & $67 \%$ & $71 \%$ & $\uparrow$ \\
\hline $\begin{array}{l}\text { Visits to } \\
\text { care/nursing } \\
\text { homes }\end{array}$ & $22 \%$ & & $56 \%$ & $86 \%$ & $\uparrow$ \\
\hline Minor surgery & $11 \%$ & & $22 \%$ & $0 \%$ & $\downarrow$ \\
\hline $\begin{array}{l}\text { Duty (on-call) } \\
\text { roles }\end{array}$ & $0 \%$ & & $0 \%$ & $0 \%$ & $\leftrightarrow$ \\
\hline \multicolumn{6}{|c|}{ Activities outside of clinical contact } \\
\hline $\begin{array}{l}\text { Results } \\
\text { handling }\end{array}$ & $22 \%$ & & $89 \%$ & $43 \%$ & $\downarrow$ \\
\hline $\begin{array}{l}\text { Processing } \\
\text { incoming } \\
\text { letters/reports }\end{array}$ & $0 \%$ & & $67 \%$ & $43 \%$ & $\downarrow$ \\
\hline $\begin{array}{l}\text { Generating } \\
\text { outbound } \\
\text { letters/reports }\end{array}$ & $0 \%$ & & $67 \%$ & $29 \%$ & $\downarrow$ \\
\hline $\begin{array}{l}\text { Quality } \\
\text { improvement } \\
\text { activities }\end{array}$ & $0 \%$ & & $44 \%$ & $71 \%$ & 个 \\
\hline MDT meetings & $22 \%$ & & $44 \%$ & $43 \%$ & $\leftrightarrow$ \\
\hline $\begin{array}{l}\text { Teaching } \\
\text { others }\end{array}$ & $0 \%$ & & $11 \%$ & $43 \%$ & $\uparrow$ \\
\hline
\end{tabular}

\section{Acceptability of the intern among the primary care team}

Upon internship completion, most host-practices were overwhelmingly positive about their intern; they demonstrated good clinical skills and performed well in a variety of scenarios. Acceptability of interns grew as initial reservations from some primary care team members eased. Reservations often arose from nursing staff and were related to potential implications of unclear role boundaries. Other concerns, from GPs, included issues regarding prescribing, accountability and supervision time pressures. Practices with previous experience of PAs (usually as students), felt that this enhanced acceptability of the intern amongst staff. Intern acceptability among practices was not always driven by increased clinical contact capacity. Pressure in GPs' working days includes the 'silent workload'; the administrative workload undertaken around full clinics, often unseen by patients and some staff. Introduction of the intern, and resultant increased requirement for supervision and blocked appointments, provided some additional time for GPs to undertake this workload. Further, the interns undertook some of the GPs' silent workload. 


\section{Box 3 Quotes illustrating views regarding the acceptability of the intern among the primary care team}

"... I actually sat watching [the PA] do a couple of quite challenging learning disability reviews which I would never have the patience to do the way [the PA] did... [the PA] was very good and I was thinking... I'd be racing through this so the patient probably had a better deal." (General Practitioner)

"That's what our nurse was asking as well. What is it [the PA] will do? And I couldn't answer that question. I said time will answer I think" (General Practitioner)

"I don't think the nurses were keen....And I still don't think they're keen. I think they feel slightly threatened... and perhaps they feel [they] are better qualified...but, it's another skill mix isn't it?" (Practice Manager)

"I mean [the GP] and myself often refer to the silent workload...GP's have got a silent workload of the prescribing...the referrals, etc....there's a huge silent workload for the practice... all these clinical audits and stuff that requires clinical input but not particularly a GP... that's where [the PA has] been so useful" (Practice Manager)

\section{Acceptability of supervising the intern}

Intern supervision, and the related issue of trust, were important topics to practices and interns. Highintensity, close supervision was necessary for responsible GPs to build trust in the interns' capabilities. Perceptions of acceptable supervision levels appeared to be individual GP and/or practice-specific. A single salaried GP in a host-practice refused to provide clinical supervision for the intern due to perceived risks. Some GPs reviewed all intern patients for an extended period but felt over-burdened by this. Conversely, after a short induction period (a few weeks), other GPs allowed supervision to be determined by the intern and case complexity. Whilst training practices were more likely to find the supervision demands acceptable, they often had multiple dependent practitioners/trainees concurrently requiring GP support. The intern was the tipping point in some practices, who adapted their working day (e.g. reducing booked appointments) to accommodate this. Notably, multiple people requiring support from one GP created delays for some interns. Smaller practices struggled most to provide 'blocked-out' appointments to accommodate 'just-in-time' supervision, due to the relative impact on appointment capacity. The consequences of this were that interns sometimes rescheduled patients with another clinician to complete the management plan and/or felt less supported. Practices that had invested a lot of high-level supervision early on appeared more satisfied at internship end. Over the year, GP face-to-face reviews reduced, and practices and interns developed efficient and sustainable supervision and support methods which, in turn, increased acceptability of supervision. For example, protocolising care for common conditions; utilising electronic prescribing systems (sending electronic prescription requests) if no advice was needed; use of medical record screen messaging systems for brief advice; joint debrief sessions with other dependent professionals/trainees; and catch-up meetings. A mismatch in perceptions of appropriate supervision emerged: some interns felt over-observed and others under-supported. 


\section{Box 4 Quotes illustrating the acceptability of supervising PA interns}

"at the moment, it's not really working for the GPs because so much of their time is going in training... At the moment it's more work. . " (Practice Manager)

"... what I think would be more effective is if all the GP practices had one on-call doctor that wasn't seeing any patients so PAs could go to that doctor 'cause I think waiting round outside doors, knocking the doors, waiting for patients to leave - it takes consultation time and it also saves us waiting around and feeling awkward..." (PA intern)

"From my perspective it's definitely been manageable. I think there's a strong argument that [the PA intern] should get more input than [they get] really." (General Practitioner)

\section{Fit of the interns with existing primary care services}

The fit within the primary care team was challenged by imprecision in the interns' roles and conceptualisations. However, intern role-flexibility overcame this. Interns (and practice staff) recognised that their activities were a hybrid of GP and nursing roles and the interns' flexibility was highly valued and nurtured in many practices. However, in one practice it prevented identification of a specific role for the PA post-internship: "So I can't say we've had a bad experience but I can't say yes, we really want one, we can't do without one. I don't think we've found that role to fit [the PA] in."

The inability of interns to prescribe was a commonly cited barrier to integration and certainty of the relative benefit of interns/PAs compared with other professional groups (e.g. Nurse Practitioners). One practice felt that regular contact with GPs through prescription signing, slowed the intern's progression towards autonomy.

While the SPAI team provided guidance about target appointment lengths, in reality this was predominantly led by the interns' preferences. Interns were over-optimistic at the outset about the rate at which their appointments would reduce in length (Table 2). Persistence of longer appointment times was attributed to lack of patient and intern knowledge about PA appointment time norms, the need for interns to seek GP input for prescriptions, the undifferentiated nature of primary care patients, being managed in non-protocol-driven ways, and the need for longer appointments for certain activities/reviews. Despite this, GPs perceived a pressure to reduce appointment lengths to demonstrate acceptable value for money beyond the internship.

Some interns enhanced care by improving outreach to housebound patients, for example, when hostpractice nurses did not do home visits, interns did long-term condition reviews at home, and proactive reviews and clerking of nursing/care home admissions. These host-practices noted better or easier attainment of incentivised targets. 
Table 2

PA intern actual and predicted appointment lengths

\begin{tabular}{|lllll|}
\hline $\begin{array}{l}\text { Appointment } \\
\text { length }\end{array}$ & Baseline & $\begin{array}{l}\text { Baseline prediction of appointment length } \\
\text { at 3 months }\end{array}$ & Midpoint & Endpoint \\
\hline $\begin{array}{l}\text { PA interns } \\
\text { responding }\end{array}$ & 10 & 10 & 7 & 7 \\
\hline 30 minute & 8 & 2 & 0 & 1 \\
\hline 20 minute & 2 & 2 & 7 & 4 \\
\hline 15 minute & 0 & 6 & 0 & 2 \\
\hline 10 minute & 0 & 0 & 0 & 0 \\
\hline
\end{tabular}

\section{Acceptability of interns to patients}

Most patients had confidence and trust in their intern (Table 3); positivity stemmed from the intern:

- Having protracted appointment length

- Demonstrating a caring and listening approach

- Seeking second opinions when needed

Patient acceptability was also indirectly indicated through repeat appointments with interns. One patient was dissatisfied by being care-navigated to the intern, but this related to the patient's preference for a GP rather than the care provided by the intern per se. Some practices noted the value of proactive intern promotion of patient acceptance: engaging the patient participation group (PPG) and developing a leaflet. PPG members needed reassurance about the origins of the internship (i.e. workforce development), rather than a practice-level cost-cutting exercise. Some large teaching host-practices believed that patients generally accepted that they may see a variety of professionals. 
Table 3

Patient feedback regarding the care they experience from PA interns

\begin{tabular}{|llll|}
\hline $\begin{array}{l}\text { Aspect of care } \\
\text { (no. of respondents) }\end{array}$ & $\begin{array}{l}\text { (Very) } \\
\text { good }\end{array}$ & $\begin{array}{l}\text { Neither good nor } \\
\text { poor }\end{array}$ & $\begin{array}{l}\text { (Very) } \\
\text { poor }\end{array}$ \\
\hline $\begin{array}{l}\text { Overall, how would you describe your experience with the } \\
\text { PA? }(\mathrm{n}=160)\end{array}$ & $\begin{array}{l}158 \\
(99 \%)\end{array}$ & $1(<1 \%)$ & $1(<1 \%)$ \\
\hline How good was the PA at... & & & 0 \\
\hline ...giving you enough time? $(\mathrm{n}=160)$ & $\begin{array}{l}160 \\
(100 \%)\end{array}$ & 0 & $1(<1 \%)$ \\
\hline ...treating you with care and concern? $(\mathrm{n}=160)$ & $\begin{array}{l}158 \\
(99 \%)\end{array}$ & $1(<1 \%)$ & 0 \\
\hline ...istening to you? $(\mathrm{n}=160)$ & $\begin{array}{l}157 \\
(98 \%)\end{array}$ & $3(2 \%)$ & $1(<1 \%)$ \\
\hline ...explaining tests and treatments? $(\mathrm{n}=158)$ & $\begin{array}{l}155 \\
(98 \%)\end{array}$ & $2(1 \%)$ & $1(<1 \%)$ \\
\hline ...involving you in decisions about your care? $(\mathrm{n}=159)$ & $\begin{array}{l}154 \\
(99 \%)\end{array}$ & $4(3 \%)$ & \\
\hline
\end{tabular}

\section{Solutions offered to improve acceptability of interns}

Host-practices saw interns as an acceptable addition to the primary care workforce. They stressed that, to optimise the primary care PA value and acceptability, a continued commitment from NHSE and HEE and accurate, realistic information for practices was needed. This should include recognition of, and support for, high-intensity GP supervision for new PAs. A commitment to a national scheme was requested, to provide standardised education, practical and financial support to make the integration of PAs into primary care a success. This was felt to be necessary for at least a few years, until a critical mass of experienced primary care PAs is realised. Host-practices wanted a collaborative network to develop a shared understanding and standardised approaches to supporting their interns.

\section{Box 5 Quotes illustrating solutions offered by practices to improve acceptability of PAs interns}

"NHS England need to stop looking short-term. If they're gonna make a PA a proper role, and why wouldn't they, then they need to build that into their kind of workforce modelling and look at five or 10 years not 18 month rolling." (General Practitioner)

\section{Discussion}

PAs are part of the UK primary care workforce. Interns were acceptable and had a positive impact within the primary healthcare team, particularly due to their flexibility towards their roles and activities, however, they were not ready for quasi-autonomous primary care work. High-intensity supervision in the early 
months increased short-term burden on practices. Further, interns' dependent status carried risks and responsibilities for supervising GPs. These could prove unacceptable to practices with limited or overstretched GP capacity. Smaller and non-training practices reported the most difficulty with providing high-intensity supervision. SPAl substantially mitigated against many of these issues through the additional resource, subsidised internship posts, and training provision.

No clear definition or description of a PA was provided, in particular their specific role and professional 'identity'. This was compounded for interns who, from the host-practice perspective, were working in an unfamiliar role (PA) and in a novel support model (the SPAl). Patient feedback indicated that, whilst patients were accepting of the professional they consulted, they lacked understanding about PAs. This opacity proved confusing for the wider practice team during care navigation. The need for a change in traditional, GP-focussed patient attitudes and workforce culture was highlighted. Disseminating the unique strengths of the PA role may help to address this.

There is potential dissonance between the apparent drivers of patient satisfaction (e.g. prolonged appointments, provision of second opinions) and drivers for practices wanting an intern (to increase capacity). It remains unknown whether such high patient acceptability will persist outside of the SPAI for new PAs and optimisation of cost-per-contact by reducing appointment times.

\section{Comparison with existing literature}

This evaluation echoes previous descriptors of primary care PAs supporting, rather than replacing, GPs and as being acceptable to patients and professionals[10,14]. However, this evaluation presents a slightly different view of their primary care activities, previously documented as predominantly acute assessment roles[10]. Within the SPAI, practices had shifted intern activities away from solely BOD appointments to reduce supervision burden. While existing literature identifies PAs as providing more care for less outlay, compared to GPs, costs associated with GP interruptions, the necessary supervision, and ongoing need for GPs to sign prescriptions importantly were not accounted for[10]. This evaluation suggests these factors are likely to impact on economic benefits of new PAs within primary care. The provision of adequate 'just-in-time' supervision is beneficial in the primary care setting[15] and should be recognised for such developmental roles. Although existing literature outlines the benefit of the flexibility of roles that primary care PAs are capable of undertaking[10], there is limited information elsewhere reporting primary care roles outside of acute assessment. This is notable given the broad range of clinical and non-clinical activities undertaken by interns in this evaluation, and so should be factored into future economic analyses and descriptors of the role of primary care PAs. The identified expectationpreparedness gap was not previously highlighted and was possibly magnified by national primary-care facing documentation[13] describing the role of established primary care PAs, possibly in contexts in which PAs are afforded wider rights. Further, confusion between dependent and quasi-autonomous working of PAs may also have been perpetuated by national descriptions of the role[16].

\section{Strengths and limitations of this study}

Page 12/16 
This service evaluation is valuable as it describes the novel SPAI for new PAs entering primary care and ongoing feedback to relevant stakeholders has enabled findings to shape future internship cohorts and new internships in real time. This evaluation builds on previous empirical work to develop an understanding of the UK context which is crucial at this time of significant policy-driven change. All interns provided data at least once, and only one practice did not participate. Limitations are that participants were not required to complete every element of data collection, that patient satisfaction data were obtained by only five of the eight practices, and that the pragmatic design (adopted to maximise engagement) meant that exact resource use (both time and financial) could not be evaluated.

\section{Recommendations for practice and policy}

With appropriate supervision and support to develop as healthcare professionals, new PAs appear to be a suitable and acceptable addition to the UK primary care workforce. The lessons learned within this evaluation are likely to be transferrable to new PAs taking on PCN roles. Central support, guidance and regulation needs further to be clarified to optimise the acceptability and sustainability of integrating new PAs into the national primary care workforce. The interns required high-intensity supervision; placing new PAs into practices facing a critical workforce crisis is likely to be detrimental to both intern and practice[10]. In general, larger, training practices appeared to be the optimal host organisations for new PAs as they had existing transferrable development skills and greater capacity to absorb high-intensity supervision.

\section{Conclusions}

PA Interns working within a supported and subsidised primary care-focussed internship model were acceptable to patients and practices. However, as new PAs, they were unprepared for this role. This testof-concept SPAI has highlighted that, to ensure successful integration of new PAs into primary care and to support them to reach their full potential, commitments to longer-term, sustainable, cohesive and appropriately funded schemes, including structured and standardised education and supervision, need to be delivered. Without such investment, there is a risk that acceptability of PAs in primary care, and PAs' views of primary care careers, will be undermined before the profession has attained its full potential.

\section{Abbreviations}

$\mathrm{BOD}=$ book on day

$\mathrm{GP}=$ general practitioner

$\mathrm{HEE}=$ Health Education England

$\mathrm{HEI}=$ Higher Education Institution

$\operatorname{NHSE}(\& l)=$ NHS England (and improvement) [was NHSE at the time of the evaluation) 
$\mathrm{PA}=$ physician associate

$\mathrm{PCN}=$ primary care network

PPG = patient participation group

SPAI = Staffordshire Physician Associate Internship

\section{Declarations}

\section{Ethical Approval:}

Ethical approval was not required for this service evaluation. Participants were provided with information about what would happen to their data prior to participation.

\section{Availability of data and materials}

The datasets used and/or analysed during the current study are available from the corresponding author on reasonable request.

\section{Competing interests:}

ST, EC, and JE were all GP partners at practices hosting a PA intern in the evaluated cohorts.

\section{Funding:}

Funding for the Staffordshire Physician Associate Internship, and for employing the Physician Associate Interns, was provided by NHS England, Health Education England, the host employing Trust and individual host primary care practices. This evaluation was funded separately by Health Education England.

\section{Authors' contributions:}

EC, JE, SL and MA designed the evaluation. ST, LM, ASJ and MA designed the internship and facilitated the evaluation to take place. EC undertook all data collection. EC and VS undertook primary data analysis. All authors have contributed to the writing of this paper.

\section{Acknowledgements:}

Thank you to the practice staff, physician associate interns and patients who were involved in providing data for this evaluation.

\section{References}


1. Faculty of Physician Associates Royal College of Physicians. Who are Physician Associates [Internet]. Vol. 2020, 2020. 2020. Available from: https://www.fparcp.co.uk/about-fpa/Who-arephysician-associates

2. Ritsema T. Facult of Physician Associate Census results 2018 [Internet]. Vol. 2019. 2018. Available from: https://www.fparcp.co.uk/about-fpa/fpa-census

3. Digital NHS. General Practice Workforce - 31 March 2020 [Internet]. Vol. 2020. 2020. Available from: https://digital.nhs.uk/data-and-information/publications/statistical/general-and-personal-medicalservices/final-31-march-2020

4. NHS England. General Practice Forward View [Internet]. Vol. 2016, NHS England. 2016. p. 60. Available from: https://www.england.nhs.uk/wp-content/uploads/2016/04/gpfv.pdf

5. NHS. NHS long term plan [Internet]. Vol. 2019. 2019. Available from: https://www.longtermplan.nhs.uk/

6. British Medical Association. Creating and running primary care networkds (PCNs) [Internet]. Vol. 2019. 2019. Available from: https://www.bma.org.uk/collective-voice/committees/generalpractitioners-committee/gpc-england/gp-contract-agreement-england/primary-care-networkspcns/creating-and-running-pcns\#Workforce

7. NHS. Primary care networks [Internet]. Vol. 2019. Available from: https://www.england.nhs.uk/primary-care/primary-care-networks/

8. Scope of Practice Policy. Physician Assistants Overview [Internet]. Vol. 2020. 2020. Available from: http://scopeofpracticepolicy.org/practitioners/physician-assistants/

9. Roland M. The future of primary care Creating teams for tomorrow Report by the Primary Care Workforce Commission [Internet]. http://hee.nhs.uk/wp-content/blogs.dir/321/files/2015/02/Thefuture-of-primary-care-v7-webFINAL.pdf: Health Education England; 2015. Available from: https://www.hee.nhs.uk/sites/default/files/documents/The Future of Primary Care report.pdf

10. Drennan VM, Halter M, Brearley S, Carneiro W, Gabe J, Gage H, et al. Corrigendum: Investigating the contribution of physician assistants to primary care in England: a mixed-methods study. Heal Serv Deliv Res. 2016 May;2(16):137-8.

11. Lau R, Stevenson F, Ong BN, Dziedzic K, Treweek S, Eldridge S, et al. Achieving change in primary care--causes of the evidence to practice gap: systematic reviews of reviews. Implement Sci. 2016 Mar 22;11:40-4.

12. NHS. GP patient survey [Internet]. Vol. 2020. 2020. Available from: https://www.gp-patient.co.uk/

13. Royal College of General Practitioners. Royal College of General Practitioners position paper on physician associates working in general practice. [Internet]. Vol. 2019. 2017. Available from: https://www.rcgp.org.uk/policy/rcgp-policy-areas/physician-associates.aspx

14. Williams LE, Ritsema TS. Satisfaction of doctors with the role of physician associates. Clin Med. 2014 Apr;14(2):113-6.

15. Mertens F, de Groot E, Meijer L, Wens J, Gemma Cherry M, Deveugele M, et al. Workplace learning through collaboration in primary healthcare: A BEME realist review of what works, for whom and in 
what circumstances: BEME Guide No. 46. Med Teach. 2018 Feb;40(2):117-34.

16. Arshad N. Physician associates [Internet]. Vol. 65, British Journal of General Practice. 2015. p. 286. Available from: https://www.hee.nhs.uk/our-work/medical-associate-professions/physicianassociates 